É evidente que se pode ser anti-racista sem aceitar ou se integrar na polarização racial, mas entre essa perspectiva e a posição de que a "definição estreita de negritude [...] pode constituir um obstáculo à criação de um movimento amplo pelos direitos civis que atraia pessoas de classes e credos diferentes" (p. 294) há uma longa distância. Primeiro, tenho dúvidas quanto à possibilidade real de existir um "movimento amplo pelos direitos civis" com definições estreitas ou amplas acerca da negritude; segundo, a polarização, com todos os seus efeitos, desenvolvida por uma minoria atuante, antes que um obstáculo tem sido a responsável pela mudança desencadeada na realidade política racial e social brasileira.

Do ponto de vista acadêmico, concordo com a perspectiva de Sansone a favor de "uma curiosidade etnográfica" capaz, sem apriorismos, de identificar as características específicas da nossa configuração racial e cultural. Portanto, apoio inteiramente sua proposta de um olhar brasileiro sobre o Brasil, sem vergonha de aceitar a mestiçagem e a hibridez de nossa cultura, que sempre coexistiram com uma imensa injustiça social. $\mathrm{Ne}$ gritude sem etnicidade merece ser lido seja pelo vasto conteúdo histórico, antropológico e sociológico, respaldado nas investigações do autor, seja pelas posições assumidas por ele. Com certeza, o leitor não ficará isento, pois, acima de tudo, tratase de um livro que incomoda.

Jeferson BACELAR é professor do Departamento de Antropologia da UFBA e pesquisador do Centro de Estudos Afro-Orientais. E-mail: bacelarj@ufba.br

\section{Representações sociais $e$ sociedades: a contribuição de Serge Moscovici}

Serge MOSCOVICI. Representações sociais: investigações em psicologia social. Rio de Janeiro, Vozes, 2003. 404 páginas (trad. Pedrinho A. Guareschi, a partir do original em língua inglesa Social representations: explorations in social psychology [Gerard Duveen (ed.), Nova York, Polity Press/Blackwell Publishers, 2000]).

Márcio S. B. S. de Oliveira

O romeno naturalizado francês Serge Moscovici é dono de uma obra considerável, tão importante para a psicologia (seu campo de formação e atuação) como para a história e as ciências sociais. Seus trabalhos e sua teoria das representações sociais (TRS) têm influenciado ao longo das últimas quatro décadas pesquisadores tanto na Europa como nas Américas, incluindo o Brasil. ${ }^{1}$ É curioso, assim, que entre sua vasta obra - doze livros individuais e quatorze que ele organizou ou escreveu em conjunto com outros autores -, apenas dois tenham sido traduzidos para o português, ambos com edições esgotadas. ${ }^{2}$ É com prazer, portanto, que apresento ao leitor a tradução de Social representations: explorations in social psychology, terceiro livro de Moscovici.

O leitor não encontrará neste livro uma tese formalmente defendida. Ao contrário, o que se tem são capítulos independentes. Contudo, a impressão inicial de uma "coletânea" de um só autor logo se esvai. Isto porque Moscovici, desde o final dos anos de 1950 e início da década de 1960, preocupa-se com os mesmos temas, retomados em perspectiva ao longo dos seis capítulos que compõem a obra. Trata-se de temas como o processo social de produção de conhecimento, a definição de sociedade e a discussão em torno das representações sociais. No interior das ciências sociais, sua obra pode ser inserida no campo da sociologia do conhecimento; e acredito que esta classificação, embora reducionista, não desagradaria ao autor. Reducionista porque Moscovici se 
interessou não apenas em compreender como o conhecimento é produzido, mas principalmente em analisar seu impacto nas práticas sociais e vice-versa. Em suas próprias palavras, interessouse no "poder das idéias" de senso comum, isto é, no "estudo de como, e por que as pessoas partilham o conhecimento e desse modo constituem sua realidade comum, de como eles transformam idéias em práticas [...]" (Moscovici, apud Duveen, p. 8). Em síntese, preocupou-se em compreender como o tripé grupos/atos/idéias constitui e transforma a sociedade.

O tema da relação entre grupos, atos e idéias (ou imagens) está presente desde sua tese de doutorado publicada em 1961, com reedição revisada em 1976, Psychanalyse, son image et son publique. Resgatando o conceito de representações coletivas (RC), inicialmente proposto por Émile Durkheim e, de alguma forma, esquecido por seus contemporâneos, ${ }^{3}$ o autor estudou, então, as diversas maneiras pelas quais a psicanálise era percebida (representada), difundida e propagandeada ao público parisiense. Pela discussão profícua sobre a relação entre linguagem e representação, as conclusões deste trabalho fizeram escola. Podemos sintetizá-las em três pontos fundamentais: 1) entre o que se acreditava cientificamente ser a psicanálise e o que a sociedade francesa entendia por ela existia um intermediário de peso, as representações sociais; 2) essas representações não eram as mesmas para todos os membros da sociedade, pois dependiam tanto do conhecimento de senso comum (ou popular), como do contexto sociocultural em que os indivíduos estavam inseridos; e 3) no caso de novas situações ou diante de novos objetos, como, por exemplo, a psicanálise, o processo de representar apresentava uma seqüência lógica: tornar familiares objetos desconhecidos (novos) por meio de um duplo mecanismo então denominado amarração - "amarrar um barco a um porto seguro", conceito que logo evoluiu para sua congênere "ancoragem" -, e objetivação, processo pelo qual indivíduos ou grupos acoplam imagens reais, concretas e compreensíveis, retiradas de seu cotidiano, aos novos esquemas conceituais que se apresentam e com os quais têm de lidar.
A reflexão de Moscovici, contudo, não parou aí. Ele quis compreender como a produção de conhecimentos plurais constitui e reforça a identidade dos grupos, como influi em suas práticas e como estas reconstituem seu pensamento. O autor insistiu sobre este assunto em dois outros livros. Em Psychologie des minorités actives, ${ }^{4}$ mostrou como os processos de mudança social são influenciados não apenas por grupos majoritários, mas também por grupos minoritários (ou minorias); já em A máquina de fazer deuses (La machine à faire de dieux,1988), chamou a atenção para o esquecimento da dimensão psicológica por parte das teorias sociológicas tradicionais. Em ambos os livros, Moscovici trabalhou pelo reconhecimento de processos de mudança social levemente autônomos do sistema social e mais dependentes das ações de indivíduos e grupos (mesmo minoritários) e de suas "situações sociais".

Representações sociais: investigações em psicologia social retoma essas grandes questões. Constitui-se dos principais ensaios "extraídos de um corpo bem maior de trabalho", e é finalizado com uma longa entrevista de Moscovici a Ivana Marková, momento privilegiado em que se pode observar como o autor explica seus conceitos não só em relação à época em que foram escritos, como também da perspectiva de quem estudou diversas formas pelas quais sua obra foi recebida.

O conjunto desses ensaios/capítulos fornece uma clara idéia do caminho intelectual trilhado pelo autor e retoma o permanente diálogo mantido com as ciências sociais. Não obstante poderem ser lidos na ordem que se desejar, uma certa lógica os fundamenta. Comento-os sem respeitar sua ordem numérica, buscando reconstruir a identidade teórica que os anima.

O capítulo 2 - "Sociedade e teoria em psicologia social" - é, para aqueles pouco afeitos ao jargão da psicologia, bastante informativo. O autor apresenta como a psicologia social de origem européia se encontra numa situação de redescoberta de seu campo, tendo em vista as contribuições dos norte-americanos nesta área, ${ }^{5}$ as quais, segundo o autor, não foram propriamente de ordem teórica ou metodológica, mas se deram em um plano mais específico e concreto da realidade daquele país. Ou 
seja, eles inscreveram suas análises no contexto social que as viu nascer, enquanto os europeus talvez mais empenhados na luta para afirmar seu próprio campo científico - se afastaram de seus problemas sociais cotidianos. Em conseqüência, aos psicólogos europeus, diferentemente do que ocorreu em relação aos sociólogos, não foi cobrada uma posição crítica ou de mudança em relação à sociedade, uma vez que passaram a ser considerados "administradores de resistências". Moscovici mostra os perigos sociais e os limites científicos dessa postura e clama por uma maior interação da psicologia - indicando inclusive os psicólogos que mais têm contribuído para isso - com todas as ciências sociais, em especial a sociologia, para a qual as noções de mudança, conflito e poder são centrais. O autor repassa, enfim, estudos sociopsicológicos pouco conhecidos entre nós talvez porque tenham sido autoclassificado como comportamentais e não como sociais. Mas isso era apenas uma estratégia em relação aos fundos de pesquisa; na verdade, esses estudos podem ser vistos como de aplicação da psicologia sobre fenômenos de sociedade. Portanto, muito úteis às ciências sociais.

O capítulo 5 - "Caso Dreyfus, Proust e a psicologia social" - é um belo ensaio sobre a importância da psicologia social como ferramenta de análise. O autor analisa aqui o "caso Dreyfus" - até hoje uma referência quando se pensa em sociedade partida, dilacerada, mas à procura de um outro arranjo social. Proust também levanta essa discussão em sua obra literária, o que torna muito pertinente Dreyfus e Proust estarem juntos neste ensaio. O "caso Dreyfus", ao revelar uma sociedade em busca de um "novo ideal", torna-se, em Moscovici, um excelente motivo não só para resgatar a original noção durkheimiana de "consciência coletiva" (ou "forças coletivas"), mas também para testar os limites explicativos da noção de "padrão geral de comportamento" que atua sobre o conjunto da sociedade, independentemente das inserções e das trajetórias sociais. A discussão em torno desse conceito durkheimiano está presente também no capítulo 3, "A história e a atualidade das representações sociais".

Neste capítulo, o leitor encontra uma discussão refinada (esboçada já no primeiro capítulo) so- bre pensamento primitivo, senso comum e ciência. Qualquer uma dessas práticas mentais (e sociais), afirma o autor, é sempre uma forma de representação. Não são realidades, mas representações dela. Portanto, segundo Moscovici, é em função das representações (e não necessariamente das realidades) que se movem indivíduos e coletividades. Saber como se formam ou como operam essas representações - onde se misturam a um só tempo pensamento primitivo, senso comum e ciência tece a trama da discussão apresentada.

Retornando às reflexões presentes em As formas elementares da vida religiosa (Durkheim, 1912), o autor mostra, primeiro, como o pensamento científico é da mesma natureza (é o corolário) dos outros dois pensamentos (primitivo e senso comum). Segundo, mostra como todas essas práticas mentais têm origem na sociedade, ou seja, são categorias sociais de pensamento. Mas isto o próprio Durkheim já havia afirmado. A diferença operada é que o autor quer descobrir, também em atos psíquicos (ou francamente individuais), origens sociais. Para tanto, propõe uma continuidade entre representações individuais e coletivas, recorrendo a Levy-Bruhl e a Vygotsky (autores também retomados no capítulo 6). Moscovici começa por afirmar que não obstante a tese durkheimiana sobre a separação entre representações individuais e coletivas estar correta, o problema encontra-se nos detalhes, nas singularidades, ou seja, no fato de que as representações coletivas tratam de fenômenos gerais e os "relacionam a práticas ou realidades que não o são" (p. 184). Esse dilema é retomado no capítulo 6. Vejamos.

"Consciência social e sua história" é um ensaio sobre Jean Piaget (1896-1980) e Liev Vygotsky (1896-1934), escrito em 1996, data do centenário do nascimento desses autores. Moscovici situa na base da mentalidade humana o ambiente natural da sociedade e as representações (individuais e coletivas) em seu contexto histórico. Retoma, assim, a discussão iniciada no capítulo 3, acrescida agora por outras interrogações, como, por exemplo, se há continuidades ou descontinuidades entre as diversas formas individuais e coletivas de ser e de representar? Para responder, Moscovici resgata tanto a evolutiva noção de representações coletivas de 
Durkheim como as inconciliáveis formas mentais do sociólogo francês Lucien Levy-Bruhl (18571939), traçando um paralelo com as obras de Piaget e Vygotsky. A análise é a um só tempo simples e profunda. Piaget teria seguido o caminho proposto por Durkheim: há evolução nas formas de representação; já Vygotsky, em desconfortável relação com o marxismo soviético de então, teria seguido Levy-Bruhl: uma mesma cultura pode gerar distintas representações, não havendo empréstimos ou substituições entre elas, mas eventualmente "saltos" ou "revoluções". O autor contextualiza este debate sobre o caráter universal ou evolucionista das representações nos anos de 1920 e em plena polêmica marxista-leninista em torno do "controle" da consciência social e do destino único das sociedades européias. As possibilidades históricas de então - tanto o marxismo como o nazismo, como bem demonstrou Karl Mannheim - foram igualmente mortíferas, abreviando assim o debate que se iniciava.

Embora o capítulo 6 retome o dilema apresentado no capítulo 3, fica-se sem saber quem teria razão, se Piaget ou Vygostky. Em outras palavras, Moscovici não diz se as múltiplas representações coletivas ou individuais são ou não interdependentes. No capítulo 3, o autor sugere que outros "epistemólogos com mais tempo que [ele] se interessem por essa particular relação" [entre os dois autores e suas teorias] (p. 193), fechando o elo que une estes capítulos.

Como os capítulos não são seqüenciais, as reflexões elaboradas nos capítulos 3 e 6 partem de um conteúdo desenvolvido nos capítulos 1 e 4 . Nesses últimos, contudo, o autor apresenta uma hipótese relativamente diferente daquela que sempre seguiu. Ele afirma que, embora sociais e historicamente localizáveis, as representações individuais e coletivas podem guardar um sentido geral que ultrapassa a sociedade que as viu nascer. Este sentido atende pelo nome conceitual de themata. Vejamos em detalhe.

Em "O fenômeno das representações sociais" (capítulo 1), Moscovici apresenta as diferenças, ora sutis ora bem evidentes, entre seu conceito e o de Durkheim a respeito das representações sociais. Duveen, editor do original inglês, na apresentação da obra afirma que a distinção operada por Durkheim entre representações individuais (objeto da psicologia) e representações coletivas (objeto da sociologia) está na origem de certa dificuldade em se definir a psicologia social como ciência e também de certa incapacidade de os psicólogos considerarem a dimensão social presente nos atos individuais. Esta é a razão de Duveen considerar Durkheim um "ancestral ambíguo" (p. 13). Quando Moscovici propõe seu novo conceito, continua Duveen, ele quer não apenas se distanciar de seu mestre, mas também "explorar a variação e a diversidade das idéias coletivas nas sociedades modernas" (p. 15).

A substituição do termo "coletivas" por "sociais" marca, assim, a original diferença estabelecida em relação a Durkheim. A pedra de toque do argumento foi, de um lado, o estabelecimento das fraturas existentes nas "forças coletivas" e, de outro, a maneira pela qual essas fraturas impactam diversamente o cotidiano de grupos e indivíduos. De fato, no início de sua obra, Moscovici parecia oscilar entre reconhecer ou não a autonomia das idéias (ou do universo ideológico) e seu impacto sobre o comportamento coletivo. Parecia, pois, oscilar entre um pensamento primitivo que "conforma realidades" e um pensamento científico que "é conformado pela realidade" (p. 29). Entre $1961 \mathrm{e}$ 1976, o autor aponta uma solução para o problema, ao afirmar que representar é um processo de produção de conhecimento que funciona como que "rolando" por sobre estruturas sociais e cognitivas locais (e populares), sendo, portanto, sociovariável. Com esta atitude, ele parece romper definitivamente com a idéia durkeimiana de "forças coletivas" ou de "ideais" que apenas cimentam e conferem sentido às sociedades justamente quando delas se libertam para assumir uma "outra natureza”, isto é, quando se reconhece que elas "[...] têm por causas próximas outras representações coletivas e não esta ou aquela característica da estrutura social". ${ }^{7}$ Ora, para Moscovici, as representações nunca seriam de "outra natureza": elas seriam da natureza mesma dos grupos sociais que as criam, e sua eficácia - tanto prática como simbólica - dependeria dessa inserção, e não poderia jamais ter um sentido universal. Com este 
argumento, Moscovici acabou por demonstrar que as representações não derivam de uma única sociedade, ultrapassando-a, como insistiu Durkheim, mas das diversas sociedades que existem no interior da sociedade maior, e, portanto, não podem ultrapassá-la.

Entretanto, como discuti em outro artigo, ${ }^{8}$ há pouca diferença substantiva entre os termos "coletivas" e "sociais", pois ambos revelam a dimensão plural das associações humanas e a presença das idéias gerais (ou "forças coletivas") no seio da sociedade, além de indicarem a necessidade do estudo de seu impacto nos atos cotidianos e mesmo nas mudanças históricas. Moscovici, no capítulo 7 ("Entrevista"), parece concordar com isso: "Não espere que eu jamais seja capaz de explicar a diferença entre 'coletivo' e 'social" (p. 348). Trocando um termo por outro, o autor afirma ter desejado apenas enfatizar a "idéia de diferenciação, de redes de pessoas e suas interações" (Idem). O leitor pode ficar com uma idéia um pouco confusa - ou talvez se sinta aliviado em relação à mudança (evolução?) na maneira como o autor encara aqui "sua" maior inovação conceitual. Mas se poderia perguntar se esses termos são agora intercambiáveis.

A título meramente especulativo, acredito que, não mais insistindo na diferença entre "coletivas" e "sociais", o autor quer mostrar que as idéias, embora cotidianas e sociovariáveis, podem também ser universais porque se perdem na nuit des temps das sociedades - elas pré-existem à vida; são um "ambiente" social e cultural, segundo Moscovici. Em conseqüência, têm certa "autonomia" e se descolam da estrutura social e material, o que faz o autor retornar à célebre fórmula durkheimiana. É forçoso reconhecer, assim, uma inflexão no pensamento de Moscovici presente em Representações sociais. Essa inflexão atende inclusive por um novo nome - themata -, e é utilizada para descrever o conjunto desses "pensamentos-ambientes" relativamente autônomos e descolados da estrutura social.

O título do quarto capítulo - "O conceito de themata" - é, como dizem os franceses, tout un programme. Mas, o que vem a ser themata? Como o radical latino thema, cuja tradução mais literal é "o que está colocado ou o que é", o termo tal como é empregado, é um desdobramento teóricoepistemológico do conceito de representações sociais. O autor inicia sua análise afirmando que as representações sociais necessitam do "referencial de um pensamento preexistente" (p. 216). Em seguida, levanta a questão sobre como se pode "passar do microssociológico ao macrossociológico", ou, ainda, sobre qual "teoria [poderia] garantir alguma concordância entre esses dois níveis" (p. 221). Tem-se aí uma reflexão de fôlego. De fato, o principal problema de qualquer teoria em ciências humanas é justamente generalizar a partir de observações locais. A discussão proposta pelo autor é tão ou mais importante quando se sabe que estudos empíricos no campo da teoria das representações sociais apresentam certa incapacidade de passar da micro à macrosociedade. Depois de mapeá-las, esses estudos deixam a desejar ao tentar qualificar as representações. A prática sociológica, por vezes, padece do mesmo mal. No entanto, refugia-se sabiamente em suas referências clássicas (Marx, Simmel, Durkheim, Weber, Pareto, entre outros). Aqueles que, da filosofia à antropologia, trabalham com a noção de imaginário encontram-se nessa mesma sintonia - relutam em aceitar um excessivo relativismo cultural. Procuram, pois, sentidos gerais.

A resposta de Moscovici, neste momento de sua carreira e obra, não deixa de ser intrigante e instigante. Para alguém que construiu toda sua reflexão em torno do tema da "diversidade das sociedades", como pensar em themata, ou seja, como pensar na existência de temas gerais que abracem e confiram sentidos a toda pluralidade social? Por meio de esquemas explicativos com conceitos e um "esquema" que em nada deixam dever ao melhor da lógica científica francesa, Moscovici demonstra progressivamente como isso se "materializa", ou seja, como o themata opera e qual seu impacto na dinâmica social. De maneira corajosa o autor afirma: "Na Sociologia e na Antropologia, os temas ou análises temáticas expressam uma regularidade de estilo, uma repetição seletiva de conteúdos que foram criados pela sociedade e permanecem preservados pela sociedade." Contudo, "[...] a noção de tema indica que a possibilida- 
de efetiva de sentido vai sempre além daquilo que foi concretizado pelos indivíduos, ou realizado pelas instituições" (p. 224). Uma "regularidade de estilo", um sentido que ultrapassa indivíduos e instituições? Deve-se, portanto, olhar as regularidades históricas como o fez Weber? Sim, afirma o autor. Entretanto, no momento de explicar essa "regularidade de estilo" (o themata), há mais percurso que chegada, mais vontade que materialidade. Isto porque, como salienta cautelosamente o autor, "[...] seria perigoso tentar e apresentar como um resultado comprovado algo que, para o momento, é apenas um horizonte" (223). E Moscovici praticamente aborta aí sua reflexão.

Não quero me arriscar a completar um raciocínio que não é meu, nem há espaço para isso. No entanto, parece-me que o conceito de themata retoma o central debate em torno da "autonomia do universo ideológico". As idéias (individuais ou coletivas) teriam como pressuposto "outras idéias" sociais. Em linguagem sociológica, só fatos sociais podem explicar fatos sociais. Assim, depois de trabalhar arduamente na inserção social das idéias em grupos e práticas historicamente determinadas, Moscovici volta seu interesse para o debate em torno da antigüidade e da permanência de certos temas no cotidiano das relações sociais. Detém-se, assim, na generalidade flutuante dos "temas gerais", pouco importando se eles se manifestam em indivíduos ou em coletividades.

Em sua carreira, o autor inclinou-se ora em direção à generalidade, ora em direção à singularidade. Ora para a continuidade dos "temas gerais", ora para a particularidade irredutível dos atos individuais. Isso porque, para ele, há sempre indivíduo e sociedade. No que se refere, contudo, à polêmica entre os termos "coletivas" e "sociais", o autor afirma de maneira não menos cautelosa: "não se deve multiplicar conceitos sem necessidade" (p. 348). Nesse sentido, pouco importaria se as representações são coletivas ou sociais, pois todo o problema residiria em saber, então, se elas revelam ou não a presença de themata.

Algumas interrogações podem agora fazer o ofício de síntese desta resenha. Vejamos: Instituições coercitivas totais ou diversidade de associações sociais? Dinâmicas sociovariáveis ou sistemas unificadores? Sociedade global ou localidades a serem narradas? Talvez essas aparentes antíteses (ou "antinomias") estejam por detrás do conceito de themata. Este seria, assim, a resposta-sentido que nos permite ver o detalhe e a generalidade em cada investigação particular, sem perder de vista a dimensão social presente em ambos. Em resumo, temos, de um lado, a impossibilidade de renunciar à generalização e, de outro, a necessidade do paciente trabalho de descrição das particularidades. Que a reflexão de Moscovici seja um convite para retomarmos o prazer sociológico de olhar o todo sob o abrigo da milenar paciência da construção do detalhe. É a isto, acredito, que esta obra nos incita.

\section{NOTAS}

1 Desde 1998, foram organizadas, somente no Brasil, três jornadas internacionais sobre representações sociais, a última delas no Rio de Janeiro em 2003.

2 A Representação social da psicanálise (Rio de Janeiro, Zahar, 1978 [1961/1976]) e A máquina de fazer deuses (Rio de Janeiro, Imago, 1990).

3 A esse respeito, ver Márcio de Oliveira, "Representação social e simbolismo: os novos rumos da imaginação na sociologia brasileira”, Revista de Ciências Humanas, 7/8: 173-193, Curitiba, Editora da UFPR, 1999.

4 Paris, PUF, 1979/1996.

5 A esse respeito, ver o excelente livro de Amalio Blanco Abarca, Cinco tradiciones en la psicologia social (Madri, Morata, 1994).

6 Alfred Dreyfus (1859-1935), capitão do EstadoMaior Geral do Exército francês foi acusado de ter entregado à Alemanha documentos referentes à defesa francesa. Dreyfus foi julgado, condenado a prisão perpétua em 1894 e deportado para a Ilha do Diabo (Guiana Francesa). Foi finalmente libertado em 1906, quando se provou sua inocência. Como Dreyfus era judeu e o julgamento inconsistente, o caso provocou uma forte onda de anti-semitismo, dividindo a opinião pública francesa. Emile Zola e Emile Durkheim, entre outros, foram "partidários de Dreyfus". 
7 Cf. E. Durkheim, Sociologia e filosofia (São Paulo, Ícone, 1994, p. 50). Sobre o debate em torno da natureza das representações coletivas e suas diferenças em relação às representações individuais, ver, ainda, os prefácios da primeira e da segunda edição do livro As regras do método sociológico. São Paulo: Companhia Editora Nacional, 1977 [1895] e Steven Lukes, "Bases para a interpretação de Durkheim", em Conh, G (org.), Para ler os clássicos (Rio de Janeiro/São Paulo, Livros Técnicos e Científicos, 1977, pp. 15-46).

8 "Representações sociais: uma teoria para a sociologia?" III JIRS, Rio de Janeiro, 2 a 5/9/2003. Este texto, revisado e ampliado, será publicado no próximo número da Revista de Estudos de Sociologia, da UFPE.

\section{MÁRCIO S. B. S. DE OLIVEIRA é doutor em Sociologia, professor e coordenador do Pro- grama de Pós-graduação em Sociologia do Departamento de Ciências Sociais da UFPR. E-mail: marciodeoliveira@ufpr.br}

\section{Tendências contemporâneas nos estudos da emigração brasileira para os Estados Unidos e Canadá}

Ana Cristina BRAGA MARTES e Soraya FLEISCHER (orgs.). Fronteiras cruzadas: etnicidade, gênero e redes sociais. São Paulo, Paz e Terra, 2003. 300 páginas.

\section{Clémence Jouët-Pastré}

Ao reunir autores de diferentes disciplinas, afiliações teóricas e nacionalidades, Ana Cristina Braga Martes e Soraya Fleischer fazem uma importante contribuição não só aos estudos da emigração brasileira, mas também aos estudos dos fluxos migratórios internacionais.

Os capítulos do livro estão fortemente vinculados, uma vez que examinam as mudanças nas correntes migratórias e a formação de novos perfis dos cidadãos brasileiros residentes nos Estados Unidos e no Canadá sob as perspectivas da etnicidade, do gênero e das redes sociais. Como várias pesquisas já indicaram (Margolis, 1994; Sales, 1999; Martes, 2000), no início da emigração brasileira em grande escala - meados dos anos 1980 -, os emigrantes tendiam a vir para os Estados Unidos a fim de permanecer no país por um curto período de tempo, apenas o suficiente para fazer algumas economias e voltar ao Brasil com a esperança de ter uma vida melhor. Os autores de Fronteiras cruzadas apresentam diversas evidências que apontam que a população brasileira nos Estados Unidos e no Canadá está se transformando, passando de transiente a estável.

No capítulo de abertura, Christopher Mitchell usa o conceito de transnacionalismo para estudar a população brasileira imigrante. Comparando-a com a mexicana, a dominicana, a haitiana, a salvadorenha e a guatemalteca, Mitchell conclui que os brasileiros apresentam um índice bastante baixo de transnacionalismo, ou seja, ainda não estão bem desenvolvidos os laços interfronteiriços que requerem redes sociais fortes nos países emissores e receptores, bem como "o êxito de uma organi- 